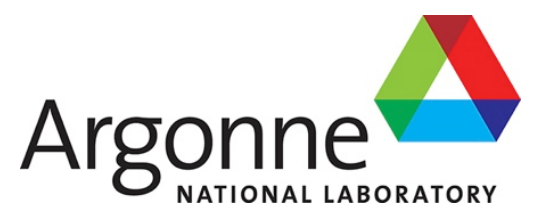

ANL-SMR-9

\title{
Assessment of Regulatory Technology Gaps for Advanced Small Modular Sodium Fast Reactors
}

Nuclear Engineering Division 


\begin{abstract}
About Argonne National Laboratory
Argonne is a U.S. Department of Energy laboratory managed by UChicago Argonne, LLC under contract DE-AC02-06CH11357. The Laboratory's main facility is outside Chicago, at 9700 South Cass Avenue, Argonne, Illinois 60439. For information about Argonne and its pioneering science and technology programs, see www.anl.gov.
\end{abstract}

\title{
DOCUMENT AVAILABILITY
}

Online Access: U.S. Department of Energy (DOE) reports produced after 1991 and a growing number of pre-1991 documents are available free via DOE's SciTech Connect (http://www.osti.gov/scitech/)

Reports not in digital format may be purchased by the public from the National Technical Information Service (NTIS):

U.S. Department of Commerce

National Technical Information Service

5301 Shawnee Rd

Alexandria, VA 22312

www.ntis.gov

Phone: (800) 553-NTIS (6847) or (703) 605-6000

Fax: (703) 605-6900

Email: orders@ntis.gov

Reports not in digital format are available to DOE and DOE contractors from the Office of Scientific and Technical Information (OSTI):

U.S. Department of Energy

Office of Scientific and Technical Information

P.O. Box 62

Oak Ridge, TN 37831-0062

www.osti.gov

Phone: (865) 576-8401

Fax: (865) 576-5728

Email: reports@osti.gov

\footnotetext{
Disclaimer

This report was prepared as an account of work sponsored by an agency of the United States Government. Neither the United States Government nor any agency thereof, nor UChicago Argonne, LLC, nor any of their employees or officers, makes any warranty, express or implied, or assumes any legal liability or responsibility for the accuracy, completeness, or usefulness of any information, apparatus, product, or process disclosed, or represents that its use would not infringe privately owned rights. Reference herein to any specific commercial product, process, or service by trade name, trademark, manufacturer, or otherwise, does not necessarily constitute or imply its endorsement, recommendation, or favoring by the United States Government or any agency thereof. The views and opinions of document authors expressed herein do not necessarily state or reflect those of the United States Government or any agency thereof, Argonne National Laboratory, or UChicago Argonne, LLC.
} 
ANL-SMR-9

\section{Assessment of Regulatory Technology Gaps for Advanced Small Modular Sodium Fast Reactors}

Prepared by

David Grabaskas, Matthew Bucknor, Tanju Sofu,

Nuclear Engineering Division, Argonne National Laboratory

May 31, 2014 



\section{EXECUTIVE SUMMARY}

As part of an ongoing Regulatory Technology Development Plan (RTDP) for advanced small modular reactors, a review of the Sandia National Laboratories (SNL) report Sodium Fast Reactor Safety and Licensing Research Plan was conducted to identify technology-related barriers that would impact the licensing of a small sodium fast reactor (SFR), which could be resolved with technology development performed in conjunction with key additional regulatory interactions. While the general conclusions of the SNL report are still valid for small SFRs, a subsequent evaluation of the report recognized several areas that would benefit from regulatory clarification of requirements, as described in the following table.

\begin{tabular}{|c|c|}
\hline Topic & Licensing Gap Closure Requirements \\
\hline Codes and Models & Additional insight into the qualification of research and development codes for licensing. \\
\hline Database Quality & $\begin{array}{l}\text { Insight into the data requirements for fuel qualification, validation, and PRA } \\
\text { quantification. This includes information on the expected level of detail and quality of } \\
\text { data from past experiments, including those that may not have been performed using } \\
\text { regulatory protocol. }\end{array}$ \\
\hline Sodium Leaks/Fires & $\begin{array}{l}\text { The regulatory response to sodium leaks/fires can drastically impact the capacity factor of } \\
\text { a plant. Additional information regarding the NRC's delineation of sodium incidents and } \\
\text { their expected response would be beneficial. }\end{array}$ \\
\hline Seismic Isolators & $\begin{array}{l}\text { Additional information, building on past interactions, regarding the necessary } \\
\text { qualification program for seismic isolators, which have not been utilized in a licensed } \\
\text { U.S. reactor. This could potentially be a crosscutting issue with other technologies that } \\
\text { need qualification, such as electromagnetic pumps and sodium-to-water heat exchangers. }\end{array}$ \\
\hline Accident Initiators & $\begin{array}{l}\text { Clarification regarding changes in the method for selecting licensing basis events (LBEs) } \\
\text { subsequent to past SFR/NRC interactions. This may include new requirements for design } \\
\text { extension conditions and seismic initiators following the Fukushima accident. }\end{array}$ \\
\hline $\begin{array}{l}\text { Mechanistic Source } \\
\text { Term }\end{array}$ & $\begin{array}{l}\text { Clarification for the definition of "adequate confidence" regarding the research and data } \\
\text { quality necessary to allow the development of a mechanistic source term. }\end{array}$ \\
\hline
\end{tabular}

The gap topics were then categorized according to their regulatory importance and projected lead time to gap closure. The results of this ranking are shown in the table below, with the codes/models, database quality, and mechanistic source term all considered essential for licensing.

\begin{tabular}{ccc}
\hline Topic & $\begin{array}{c}\text { Importance } \\
\text { to Licensing }\end{array}$ & Lead Time \\
\hline Codes and Models & High & Medium \\
Database Quality & High & Medium \\
Sodium Leaks/Fires & Low & Short \\
Seismic Isolators & Medium & Long \\
Accident Initiators & Medium & Short \\
Mechanistic Source Term & High & Long \\
\hline
\end{tabular}

Each topic was assessed in order to identify those issues that are best suited for initial regulator interaction as part of the advanced small modular reactor RTPD. The first interactions with the 
NRC will help establish the approach for resolving regulatory technology issues through the RTDP effort. Based on expert opinion, the following table provides an overview of the ranking and the reasoning behind the decision.

\begin{tabular}{|c|c|c|}
\hline Topic & $\begin{array}{c}\text { Initial NRC } \\
\text { Interaction } \\
\text { Ranking }\end{array}$ & Explanation \\
\hline Codes and Models & High & $\begin{array}{l}\text { Detailed questions regarding specific codes and models increase the } \\
\text { likelihood of constructive feedback. Guidance for LWR codes is already } \\
\text { in place. Minimal NRC input should be needed for substantial gain. }\end{array}$ \\
\hline Database Quality & High & $\begin{array}{l}\text { Detailed questions regarding specific data issues increase the likelihood } \\
\text { of constructive feedback. Many ongoing efforts involving knowledge } \\
\text { preservation. Important for fuel qualification, codes/methods validation, } \\
\text { and PRA quantification. }\end{array}$ \\
\hline Sodium Leaks/Fires & High & $\begin{array}{l}\text { Detailed questions could be presented regarding the NRC's regulatory } \\
\text { response to sodium leak/fire events. Simply establishing a dialogue with } \\
\text { the NRC concerning the topic could increase investor confidence and } \\
\text { NRC's familiarity with sodium technology. }\end{array}$ \\
\hline Seismic Isolators & Medium & $\begin{array}{l}\text { Could build on previous SAFR and PRISM discussions. Relatively well } \\
\text { known design. May be able to provide qualification requirements } \\
\text { without a detailed small SFR design. }\end{array}$ \\
\hline Accident Initiators & Low & $\begin{array}{l}\text { Can be very design dependent, reducing the likelihood of constructive } \\
\text { feedback. Substantial NRC feedback exists regarding past U.S. designs. } \\
\text { Preferred direction for LBE selection process still uncertain. }\end{array}$ \\
\hline $\begin{array}{c}\text { Mechanistic Source } \\
\text { Term }\end{array}$ & Low & $\begin{array}{l}\text { Can be very design dependent, reducing the likelihood of constructive } \\
\text { feedback. Substantial impact on all future advanced reactor designs. } \\
\text { Long lead time. Could result in postulated requirements. }\end{array}$ \\
\hline
\end{tabular}




\section{ACKNOWLEDGEMENTS}

The authors would like to thank Matthew Denman for his assistance in reviewing the Sandia National Laboratories Sodium Fast Reactor Safety and Licensing Research Plan, along with the following participants of a panel discussion to identify sodium fast reactor licensing issues: Roald Wigeland, Robert Bari, George Flanagan, Wayne Moe, and Mark Holbrook. 


\section{TABLE OF CONTENTS}

EXECUTIVE SUMMARY ............................................................................................................. I

ACKNOWLEDGEMENTS........................................................................................................ III

TABLE OF CONTENTS ........................................................................................................................IV

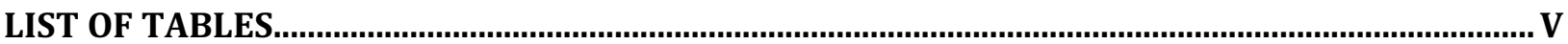

ACRONYMS.........................................................................................................................

1 INTRODUCTION ..................................................................................................... 1

1.1 ADVANCED SMALL MODULAR SODIUM FAST REACTORS ……………............................................................

1.2 RECENT NGNP/NRC INTERACTION.................................................................................................... 2

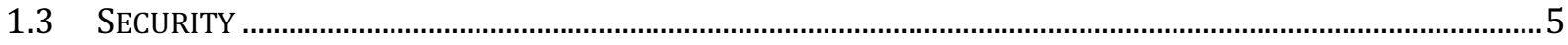

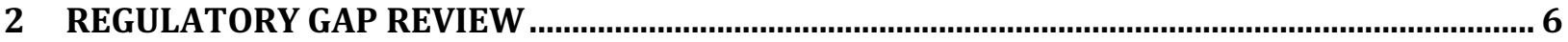

2.1 ACCIDENT SEQUENCES AND INITIATORS ..........................................................................................................

2.1.1 SNL Safety and Licensing Research Plan Summary .....................................................................................7

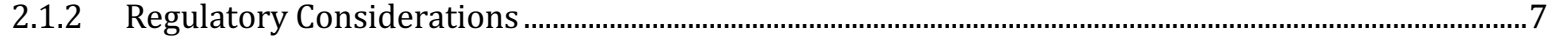

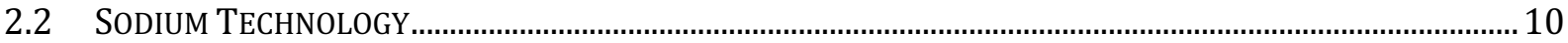

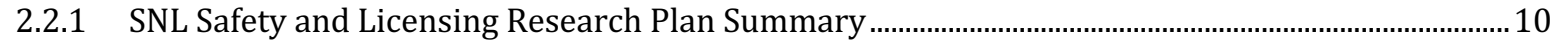

2.2.2 Regulatory Considerations...............................................................................................................................10

2.3 FUELS AND MATERIALS.....................................................................................................................

2.3.1 SNL Safety and Licensing Research Plan Summary …….......................................................................13

2.3.2 Regulatory Considerations .........................................................................................................................14

2.4 SOURCE TERM CHARACTERIZATION .............................................................................................................

2.4.1 SNL Safety and Licensing Research Plan Summary .................................................................................16

2.4.2 Regulatory Considerations ............................................................................................................. 16

2.5 CODES AND MODELS......................................................................................................................... 18

2.5.1 SNL Safety and Licensing Research Plan Summary ………..................................................................... 18

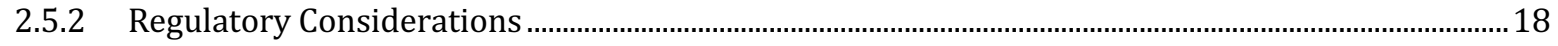

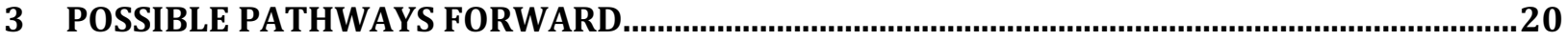

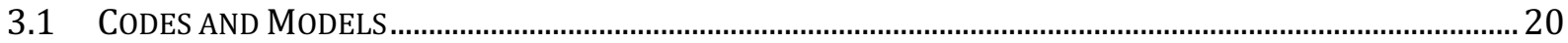

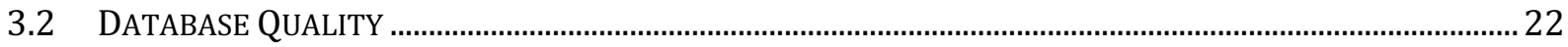

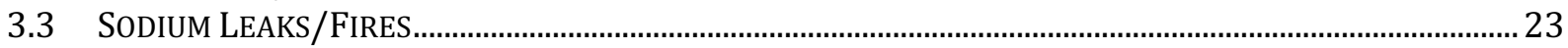

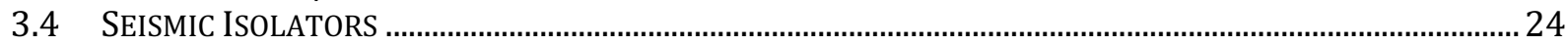

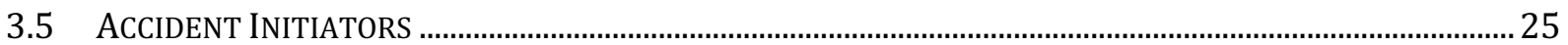

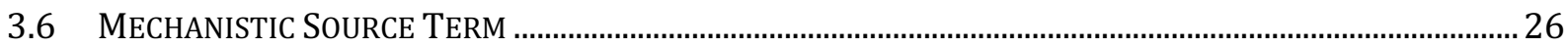

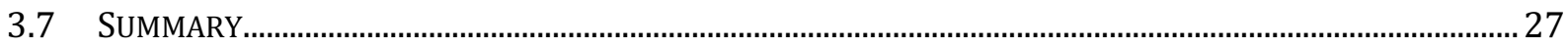

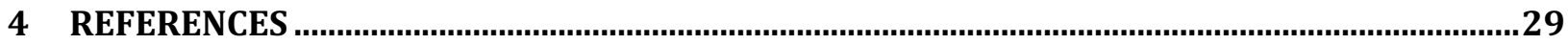




\section{LIST OF TABLES}

Table 1-1: Options for Adapting Existing NRC Technical Requirements [4] …………............... 3

Table 1-2: Summary of Relevant NGNP/NRC Interaction ........................................................ 4

Table 2-1: Accident Sequences and Initiators Gap Topical Areas from SNL Report [2] ............... 7

Table 2-2: Sodium Technology Gap Topical Areas [2] ……………………………………..... 10

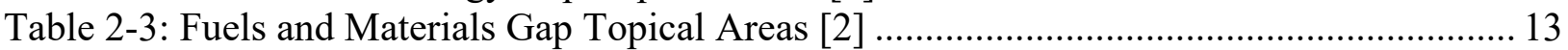

Table 2-4: Source Term Characterization Gap Topical Areas [2] …………………………...... 16

Table 2-5: Codes and Models Gap Topical Areas [2] ................................................................ 18

Table 3-1: Summary of Topic Importance and Lead Time ………………………………….... 27

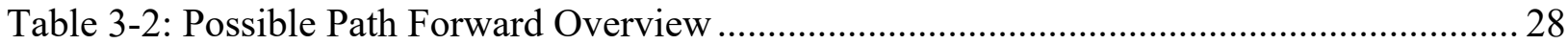




\section{ACRONYMS}

$\begin{array}{ll}\text { ACRS } & \text { Advisory Committee on Reactor Safeguards } \\ \text { ANL } & \text { Argonne National Laboratory } \\ \text { AOO } & \text { Anticipated Operational Occurrences } \\ \text { ASM-SFR } & \text { Advanced Small Modular Sodium Fast Reactors } \\ \text { BDBA } & \text { Beyond Design Basis Accident } \\ \text { CFD } & \text { Computational Fluid Dynamics } \\ \text { CRBR } & \text { Clinch River Breeder Reactor } \\ \text { DBA } & \text { Design Basis Accidents } \\ \text { DOE } & \text { Department of Energy } \\ \text { EM } & \text { Electromagnetic } \\ \text { EPZ } & \text { Emergency Planning Zone } \\ \text { FFTF } & \text { Fast Flux Test Facility } \\ \text { GE } & \text { General Electric } \\ \text { LBE } & \text { Licensing Basis Event } \\ \text { LWR } & \text { Light Water Reactor } \\ \text { NGNP } & \text { Next Generation Nuclear Plant } \\ \text { NQA } & \text { Nuclear Quality Assurance } \\ \text { NRC } & \text { Nuclear Regulatory Commission } \\ \text { PRA } & \text { Probabilistic Risk Assessment } \\ \text { PRISM } & \text { Power Reactor Innovative Small Module } \\ \text { PSER } & \text { Preliminary Safety Evaluation Report } \\ \text { PSID } & \text { Preliminary Safety Information Document } \\ \text { RTDP } & \text { Regulatory Technology Development Plan } \\ \text { SA } & \text { Severe Accidents } \\ \text { SAFR } & \text { Sodium Advanced Fast Reactor } \\ \text { SFR } & \text { Sodium Fast Reactor } \\ \text { SMR } & \text { Small Modular Reactor } \\ \text { SNL } & \text { Sandia National Laboratories } \\ & \end{array}$




\section{Introduction}

While the U.S. has a long and storied history regarding sodium fast reactor (SFR) development and operation, no SFRs have been licensed by the U.S. Nuclear Regulatory Commission (NRC). That is not to say there has been no interaction with the NRC regarding the licensing of a SFR design, as the Fast Flux Test Facility (FFTF), Clinch River Breeder Reactor (CRBR) project, General Electric's (GE) Power Reactor Innovative Small Module (PRISM), and Rockwell International's Sodium Advanced Fast Reactor (SAFR) all had NRC reviews, but none of these projects were formally licensed by the NRC. Although these past experiences present a starting point for future SFR applicants, decades have passed and the regulatory landscape has since evolved. In an effort to clarify those regulatory issues still outstanding, a review of advanced small modular sodium fast reactors (ASM-SFRs) technological licensing issues was conducted as part of a recently initiated Regulatory Technology Development Plan (RTDP) for advanced small modular reactors.

The RTDP seeks to establish an approach for interactions with the NRC to gain regulatory feedback about anticipated advanced small modular reactor licensing research and development needs, including those associated with ASM-SFRs. The identification of technological gaps related to regulatory requirements is a key output that will benefit any future ASM-SFR applicant. This is not the first time such an effort has been undertaken, as an RTDP was developed for the high-temperature gas-cooled reactor in the mid-1980s [1].

The current RTDP effort does not have to start from scratch, as a recent Sandia National Laboratories (SNL) project assessed the gaps associated with establishing the safety basis within the SFR knowledge and experience base that would pose challenges to the licensing of a SFR in the U.S. The findings of that project were documented in the Sodium Fast Reactor Safety and Licensing Research Plan [2], which proposed potential safety and licensing R\&D priorities for the U.S. Department of Energy (DOE). While that report is an excellent source of information regarding the current state of SFR knowledge and research capabilities (as validated in this report), it is presented through the framework of DOE research and development needs, rather than the licensing process per se. The effort documented here entailed translating the information within the SNL report into a regulatory action plan specific for ASM-SFRs. This information will then be used as part of the larger advanced small-modular reactor RTDP project.

\subsection{Advanced Small Modular Sodium Fast Reactors}

While the SNL gap analysis report focused on SFRs in general, the current effort centers on ASM-SFRs. There are a host of potential differences that separate ASM-SFRs from their larger counterparts. Some of these differences relate more to the economics of the reactor design than licensing matters, such as modular construction, but many issues are crosscutting, including the desire for smaller emergency planning zones (EPZs), longer refueling cycles, smaller staff, and even multi-reactor power conversion systems. Part of the current effort involved reviewing the conclusions reached in the SNL gap analysis report for potential shortcomings when translating the results to ASM-SFRs.

While ASM-SFR designs may not benefit from the "economy of scale," they reduce the financial risk through lower initial capital cost requirement and advantages of modular construction. Lower 
operation costs due to reduced staffing can also contribute to cost savings over the life of the plant. Among various ASM-SFR design efforts, more notable concepts include GE's PRISM reactor, Toshiba's 4S reactor, and Advanced Reactor Concept LLC's ARC-100 concept.

Like the larger SFRs, ASM-SFRs rely on advanced features (such as the use of passive safety features that utilize gravity-driven or natural convection systems) that affect the operation, safety, and security of the plant. The small size makes the use of such systems potentially more viable due to larger safety margins. Higher fuel burnup rates can significantly increase the period between refueling and reduce the amount of waste, possibly decreasing the overall lifecycle cost of the plant. These designs also pose a smaller source term, decreasing the potential offsite consequences in the event of hypothetical accidents. This may allow ASM-SFRs sites to have smaller EPZs.

Reduced plant size offers opportunities for below-grade siting, allowing the vital safety equipment, and/or spent fuel to be located underground, which may decrease its vulnerability to aircraft impact. While potential factory fabrication of the modular units offers some cost advantages, this concept also poses some regulatory uncertainties especially in terms of transport of fuel (possibly as core cartridges). Similarly, operation of multi-module units (i.e., units that potentially share power conversion systems, safety systems, control rooms, etc.) is an untested concept under the current regulatory framework.

\subsection{Recent NGNP/NRC Interaction}

Since its initiation as a result of the Energy Policy Act of 2005 [3], the Next Generation Nuclear Plant (NGNP) Project has researched the development and operation of a Generation IV nuclear energy system. Many of the licensing-related issues addressed by NGNP are relevant to and worthy of licensing consideration by other advanced reactor types, such as SFRs. Part of the NGNP effort has included the development of a licensing strategy for the demonstration modular high-temperature gas-cooled reactor. An outline of possible licensing strategies was submitted to Congress in 2008 [4], and included four options for adapting existing NRC technical requirements for advanced reactor licensing. These options, seen in Table 1-1, range from a completely deterministic licensing basis to a new risk-informed, performance-based body of regulation.

The DOE and NRC endorsed licensing option 2 as the regulatory strategy for NGNP. However, with this choice, the report listed several licensing issues that would need to be resolved, including the following [4]:

- Requirements and criteria for functional performance of the NGNP containment as a radiological barrier

- Allowable dose consequences for the licensing basis event (LBE) categories

- Approach for using the probabilistic risk assessment (PRA) to select LBEs; establish special treatment requirements and establish defense-in-depth requirements

- Acceptable basis for event-specific mechanistic source term calculation, including siting source term. 
Table 1-1: Options for Adapting Existing NRC Technical Requirements [4]

\section{Option Description}

1 Deterministic Approach: This option uses deterministic engineering judgment and analysis to establish the licensing basis (including selection of events) and licensing technical requirements. This approach has been used for licensing operating light water reactors (LWRs) and involves no use of PRA information and insights.

2 Risk-Informed and Performance-Based Approach: This option uses deterministic engineering judgment and analysis, complemented by NGNP design-specific PRA information, to establish the licensing basis (including selecting LBEs) and licensing technical requirements. The use of the PRA would be commensurate with the quality and completeness of the PRA presented with the application.

3 Risk-Informed and Performance-Based Approach (with greater emphasis on PRA): This option places greater emphasis on the use of the NGNP design-specific PRA in complementing deterministic engineering judgment and analysis, to establish the licensing basis (including selecting LBEs) and licensing technical requirements. As in Option 2, the use of the PRA would be commensurate with the quality and completeness of the PRA presented with the application.

$4 \quad$ New Body of Risk-Informed and Performance-Based Regulations: This option would use a new body of regulations to establish the licensing basis (including selecting LBEs) and licensing technical requirements. The new body of regulations would make extensive use of the risk-informed and performance-based regulatory structure, and would require rulemaking to be implemented.

Following this decision, NGNP prepared a series of white papers documenting their proposed approaches for resolving the key licensing issues listed above. This included a frequency versus consequence curve for the selection of LBEs [5], functional containment performance requirements [6], a strategy for developing a mechanistic source term [7], and EPZ characteristics. The white papers were submitted to the NRC and several face-to-face interactions followed.

The NRC reviewed the submitted white papers; however, without the submission of a specific reactor design, the NRC would not approve the suggested approaches, but would only state whether the strategies were "reasonable." Table 1-2 summarizes the relevant NGNP proposals and the draft NRC assessment reports that were provided to the Advisory Committee on Reactor Safeguards (ACRS) for comment [8]. Formal feedback is expected from the NRC in the near future. 
Table 1-2: Summary of Relevant NGNP/NRC Interaction

Topic

Frequency vs.

Consequence Curve

for LBE Selection

\section{NGNP Proposal}

LBEs divided into three categories. Each

category is defined by its anticipated mean

annual occurrence probability. Top-level

regulatory criteria are used as an upper acceptable limit on the consequences of each

category on the frequency vs. consequence diagram.

Mechanistic Source Term Strategy

Source terms defined as the quantities of radionuclides released from the reactor building to the environment during the spectrum of LBEs. The source terms are event specific and will be determined using models of radionuclide generation and transport. These models account for fuel and reactor design characteristics, passive features, and radionuclide release barriers. A fuel development and qualification program would provide data necessary to better understand fue performance and fission product behavior.

Functional Containment Performance Criteria

Radionuclides would be retained within the fuel during normal operation with relatively low inventory released into the helium pressure boundary. Releases to the environment would be limited to meet the onsite and offsite radionuclide dose acceptance criteria at the exclusion area boundary with margin for a wide spectrum of off-normal events.

EPZ

\section{NRC Response}

LBE categories and descriptions - Reasonable

Top level criteria - Reasonable

LBE frequency limits - Reasonable

Approach - Reasonable

Planned testing and research - Reasonable

\section{NRC Comment}

Concerns related to the quality of the

PRA, since it will be the primary source of LBE selection, but reliability data may be sparse since it is a new reactor design.

The overall approach seems reasonable but depends on continued development and future fuel qualification data.
Definition - Reasonable

Approach - Reasonable

Fuel program - Reasonable

Approach - Reasonable

New NRC EPZ policy - Not at this time
The commission has not yet reviewed a set of containment performance criteria and would need a specific containment concept (and plant design) to compare to specific criteria. Also dependent on fuel qualification program results.

Staff would be open to considering future proposals by industry or preapplicants on topics such as: PRAinformed approach that includes accident dose assessment vs. distance and risk-informed criteria for determining the point at which the probability of exceeding the protective action guide values is acceptably low. 


\subsection{Security}

Security threats, such as terrorism and sabotage, were not considered by the SNL SFR Safety and Licensing Research Plan, and will not be reviewed in detail here. However, it is important to point out that this area may be given additional scrutiny by the NRC during any future SFR licensing efforts based on the comments made by the NRC staff during their review of the Generation IV International Forum's proposed SFR general design criteria [9]. The review contained the following general comments on security in SFR designs [9]:

"The safety design criteria (SDC) should explicitly address security and establish that a design of a nuclear power plant must provide protection against credible threats to the safe operation of the facility, for example, protecting against design basis threats (DBT), including a cyber attack, for radiological sabotage. The SDC should integrate design criteria for security with safety, beginning early in the design process, through construction and implementation for operations, and decommissioning. The required security measures should be based on the possession and use of special nuclear material that potentially result in risks for radiological consequences that endanger public safety and health bounded by a $D B T$ for radiological sabotage and the risk of material theft and diversion for nuclear proliferation."

Past U.S. SFR safety analyses have not examined plant security to the level of detail currently required by the NRC. 


\section{Regulatory Gap Review}

This section reviews ASM-SFR regulatory gaps, including those identified by the SNL SFR Safety and Licensing Research Plan. The following sections are organized according to the gap analysis panels formed as part of the SNL SFR Safety and Licensing Research Plan, and consist of the following five topical areas:

- Accident Sequences and Initiators

- Sodium Technology

- Fuels and Materials

- Source Term Characterization

- Codes and Models

As part of the SNL effort, a panel of experts was convened for each of the five gap areas. The panel members were primarily from the U.S. National Laboratories, with additional members from universities, international agencies, and private consulting firms. They were tasked with reviewing and ranking the importance of each topic in regard to safety and the state of the current knowledge base. From there, estimates were made on the approximate cost and time needed to close each gap.

Each of the following sections reviews the major conclusions from the SNL gap analysis report, and presents a table summarizing their findings. This is followed by an overview of regulatory considerations, including any topics related to ASM-SFRs that may not have been considered by the original gap analysis report, or new developments since the publication of the report. 


\subsection{Accident Sequences and Initiators}

\subsubsection{SNL Safety and Licensing Research Plan Summary}

In the accident sequence and initiators gap analysis, the SNL Safety and Licensing Research Plan covered the phenomena that could affect the response of a SFR to anticipated operational occurrences (AOOs), design basis accidents (DBAs), beyond design basis accidents (BDBAs), and severe accidents (SAs) [2]. The seven identified gap topical areas, along with their subtopics, can be found in Table 2-1. A detailed explanation of the criteria used to determine the ranking levels seen in the gap analysis tables can be found in Section 3.3 of the SNL gap analysis report [2].

The major conclusion from the gap analysis report was that there are no major technological gaps that would prevent the design and development of a licensing case for a SFR as long as one stays with known technology [2]. In this instance, known technology refers to the reactor and fuel designs of those SFRs built or researched by the U.S. in the past. This includes both metal and oxide fuels and pool and loop designs. However, high minor-actinide fuels are not included (as will be discussed in Section 2.3.1), nor are SFR layouts that deviate significantly from standard loop or pool SFR concepts used in past U.S. designs.

Table 2-1: Accident Sequences and Initiators Gap Topical Areas from SNL Report [2]

\begin{tabular}{|c|c|c|c|}
\hline Gap Topical Areas & $\begin{array}{l}\text { Importance to } \\
\text { Safety Within } \\
\text { Category } \\
\end{array}$ & $\begin{array}{l}\text { Experimental } \\
\text { Database }\end{array}$ & $\begin{array}{c}\text { Ability to } \\
\text { Model }\end{array}$ \\
\hline AIS01 - Steady State Intact Fuel and Fuel Changes & $\mathrm{H}$ & & \\
\hline \multirow{2}{*}{$\begin{array}{l}\text { End-of-Life (EOL) fuel composition } \\
\text { EOL predication of reactivity feedback }\end{array}$} & & M & M \\
\hline & & M & M \\
\hline \multirow{2}{*}{$\begin{array}{l}\text { AIS02 - Transition to Natural Convective Cooling } \\
\text { Sodium stratification }\end{array}$} & $\mathrm{H}$ & & \\
\hline & & $\mathrm{H}$ & M \\
\hline \multirow{2}{*}{$\begin{array}{l}\text { AIS03 - Thermal Response of Structures } \\
\text { Thermal striping }\end{array}$} & $\mathrm{H}$ & & \\
\hline & & M & $\mathrm{H}$ \\
\hline \multirow{2}{*}{$\begin{array}{l}\text { AIS04 - Decay Heat Rejection } \\
\text { Radiation heat transfer from vessels }\end{array}$} & $\mathrm{H}$ & & \\
\hline & & $\mathrm{M}$ & $\mathrm{H}$ \\
\hline \multirow{3}{*}{$\begin{array}{l}\text { AIS05 - Power Conversion Cycle } \\
\mathrm{CO}_{2}-\text { sodium chemical interaction } \\
\mathrm{CO}_{2} \text { release and impact }\end{array}$} & $\mathrm{H}$ & & \\
\hline & & $\mathrm{L}$ & $\mathrm{L}$ \\
\hline & & $\mathrm{L}$ & $\mathrm{L}$ \\
\hline \multirow{3}{*}{$\begin{array}{l}\text { AIS06 - Fuel Transient Behavior } \\
\text { Length effects on fuel performance during transients for metallic fuel } \\
\text { High-minor-actinide content fuel performance }\end{array}$} & M & & \\
\hline & & $\mathrm{L}$ & $\mathrm{H}$ \\
\hline & & $\mathrm{L}$ & $\mathrm{L}$ \\
\hline \multirow{2}{*}{$\begin{array}{l}\text { AIS07 - Severe Core Damage } \\
\text { Fuel motion, dispersal, and morphology for metallic fuel }\end{array}$} & $\mathrm{H}$ & & \\
\hline & & $\mathrm{M}$ & M \\
\hline \multirow{2}{*}{$\begin{array}{r}\text { AIS08 - Seismic Isolation } \\
\text { Seismic isolators }\end{array}$} & $\mathrm{H}$ & & \\
\hline & & $\mathrm{L}$ & $\mathrm{L}$ \\
\hline
\end{tabular}

\subsubsection{Regulatory Considerations}

The reduced sizing of ASM-SFRs does not invalidate the general conclusions of the SNL gap analysis with regards to licensing. As stated in Section 2.1.1, while the expert opinions documented in the report found no major gaps that could prevent a licensing case, the caveat is that the statement is only true if known SFR technology is used. While both metal and oxide fuels are considered in the gap analysis report, it is generally focused on metal fuel accident philosophy rather than oxide fuel. If alternative SFR designs or fuels are considered, such as fuels with high 
minor actinide content, then the knowledge status reported in the SNL gap analysis is likely overly optimistic.

While the SNL gap analysis does include AOOs, DBAs, BDBAs, and SAs, the changing regulatory environment may have an effect on the conclusions of the report. Post-Fukushima, there is likely to be increased regulatory scrutiny on BDBAs and extreme external events. The NRC has also discussed the creation of a structured "design extension condition," which would formalize the review of these events [10]. The state of knowledge associated with SFR accident sequences within these domains is less developed. The stronger regulatory emphasis on BDBAs, coupled with a desire for smaller EPZs for ASM-SFRs, may result in the requirement for demonstrations of benign termination of accident sequences that potentially lead to fuel failures. As AIS 06 and 07 show, the knowledge and experimental databases concerning this area of fuel performance is low to medium, at best. More detail regarding fuel characterization is provided in Sections 2.3 and 2.4 .

Another repercussion of the increased attention to external events following Fukushima is the possibility of changes to seismic initiator criteria. The majority of U.S. SFR designs incorporate seismic isolation of the reactor building, and as AIS08 shows, the ability to model the failure modes of seismic isolation systems is considered low. The NRC has not licensed a reactor that included seismic isolators, but there has been past NRC interaction concerning the topic of seismic isolator qualification during the preliminary safety information document (PSID) review of both PRISM and SAFR. More is said about the ability to model seismic events, along with NRC qualification of components, such as seismic isolators, in Sections 2.3 and 2.5.

As discussed in Section 1.2, NGNP presented the NRC with an alternative approach for selecting LBEs. If such a strategy were used for an ASM-SFR, it would signal an important transition from an entirely postulated LBE selection process to one predominantly based on the frequency and consequence of accident sequences. For SFRs, this change would be significant since it would ensure that the majority of LBEs have mechanistic initiators, which could exclude some severe postulated accidents sequences that were present in past analyses. Such an approach could also have ramifications on the mechanistic source term analysis, as will be detailed in Section 2.4. However, if a risk-informed LBE selection process is used, questions will arise regarding the quantity and quality of available reliability data for the PRA.

AIS 04 pertains to the topic of decay heat removal, specifically, those passive systems that remove heat through reactor vessel walls. Such decay heat removal systems could potentially create direct pathways to the environment if major failures occurred. While no major regulatory issues are foreseen based on past NRC interactions, there are differences between these system designs and the emergency core cooling systems of the current, operating LWR fleet. In general, the licensing of plants that depend heavily on passive safety systems is still relatively immature, although plant designs with passive features like Westinghouse's AP600 have successfully navigated the process. Different approaches for modeling passive system reliability have been suggested [11], but it is clear that the path forward is likely to include increased mechanistic modeling of passive system performance. 
Of all the gaps identified as part of the accident sequences and initiators analysis, perhaps the most pressing issue is one not explicitly stated in the eight gaps listed in Table 2-1. The SNL gap report recognized an immediate need for a plan to address the lack of experiments and qualified tools for use in a licensing environment. This includes reviewing past experiments in order to assess their applicability for licensing, and the updating of SFR analysis codes in order to meet quality assurance requirements. The latter issue is discussed in more detail in Section 2.5, but the availability and accessibility of past data are imperative for the licensing case of any SFR design that uses known technology. Regulatory guidance on the requirements for past data and clarification of the process to review the quality of past experiments could yield large benefits for future licensing efforts. For example, whether the NRC would accept the use of Nuclear Quality Assurance-1 (NQA-1) "Guidance on Qualification of Existing Data" [12] for past research experiments as fulfillment of the quality assurance requirements of 10 CFR 50 Appendix B [13] is not clear. 


\subsection{Sodium Technology}

\subsubsection{SNL Safety and Licensing Research Plan Summary}

The sodium technology gap analysis of the SNL Safety and Licensing Research Plan focused on the ability to model sodium fires, gas production, and sodium interaction with concrete and drop liners [2]. The analysis was organized into the seven gap topical areas found in Table 2-2. Overall, the experimental database regarding sodium interactions with concrete and liners was considered higher than the experimental database concerning sodium spray and pool fires. The ability to model many phenomena was considered low, but those models associated with major sodium spray and pool fire components (combustion, radiation, burning rate) were considered high.

Table 2-2: Sodium Technology Gap Topical Areas [2]

\begin{tabular}{|c|c|c|c|}
\hline Gap Topical Areas & $\begin{array}{c}\text { Importance to } \\
\text { Safety Within } \\
\text { Category }\end{array}$ & $\begin{array}{l}\text { Experimental } \\
\text { Database }\end{array}$ & $\begin{array}{c}\text { Ability to } \\
\text { Model }\end{array}$ \\
\hline ST01 - Sodium Spray Dynamics & $\mathrm{H}$ & & \\
\hline Single drop particle average size & & $\mathrm{M}$ & $\mathrm{M}$ \\
\hline Single drop particle size distribution & & $\mathrm{M}$ & $\mathrm{L}$ \\
\hline Pre-ignition phase dynamics & & M & M \\
\hline Basic evaporation and combustion & & $\mathrm{M}$ & $\mathrm{H}$ \\
\hline Crust formation on droplets & & $\mathrm{L}$ & $\mathrm{L}$ \\
\hline Source of sodium aerosol & & $\mathrm{L}$ & $\mathrm{L}$ \\
\hline Model radiation transfer with/from aerosols & & $\mathrm{L}$ & $\mathrm{L}$ \\
\hline Inertial impact of molten sodium & & $\mathrm{L}$ & M \\
\hline Burning of droplets on surface of sodium pool & & $\mathrm{L}$ & $\mathrm{L}$ \\
\hline $\begin{array}{l}\text { ST02 - Sodium-Fluid Interactions }\left(\mathbf{S}-\mathbf{C O}_{2}\right) \\
\text { High pressure fluid jet leak in sodium heat exchanger }\end{array}$ & $\mathrm{H}$ & $\mathrm{L}$ & $\mathrm{L}$ \\
\hline $\begin{array}{l}\text { ST03 - Sodium Surface Pool Fire on an Inert Substrate } \\
\text { Radiation net heat flux } \\
\text { Mass burning rate } \\
\text { Oxide crust behavior on pool substrate } \\
\text { Near-surface aerosol size/distribution } \\
\text { Surface aerosol production }\end{array}$ & $\mathrm{H}$ & $\begin{array}{l}\text { L } \\
\text { L } \\
\text { L } \\
\text { L } \\
\text { L }\end{array}$ & $\begin{array}{l}\mathrm{H} \\
\mathrm{H} \\
\mathrm{L} \\
\mathrm{L} \\
\mathrm{L}\end{array}$ \\
\hline $\begin{array}{l}\text { ST04 - Aerosol Dynamics } \\
\text { Sodium aerosol source term } \\
\text { Hydrolysis of peroxides }\end{array}$ & M & $\begin{array}{l}\mathrm{L} \\
\mathrm{M}\end{array}$ & $\begin{array}{l}\mathrm{L} \\
\mathrm{L}\end{array}$ \\
\hline $\begin{array}{l}\text { ST05 - Sodium-Cavity Liner Interaction } \\
\text { Liner failure pressure or thermal response } \\
\text { Reaction product swelling behavior } \\
\text { Corrosion of liner }\end{array}$ & $\mathrm{H}$ & $\begin{array}{l}\text { M } \\
\mathrm{L} \\
\mathrm{M}\end{array}$ & $\begin{array}{l}\mathrm{M} \\
\mathrm{L} \\
\mathrm{M}\end{array}$ \\
\hline $\begin{array}{l}\text { ST06 - Sodium-Concrete-Melt Interactions } \\
\text { Aerosol source term without melt } \\
\text { Inert concrete-sodium interactions without melt } \\
\text { Basaltic concrete-sodium interactions without melt } \\
\text { Limestone concrete-sodium interactions without melt } \\
\text { Sodium-concrete reaction with sodium fire } \\
\text { Fission product dissolution and partitioning in melt and gases }\end{array}$ & $\mathrm{H}$ & $\begin{array}{l}\mathrm{L} \\
\mathrm{M} \\
\mathrm{M} \\
\mathrm{M} \\
\mathrm{M} \\
\mathrm{M}\end{array}$ & $\begin{array}{l}\mathrm{L} \\
\mathrm{L} \\
\mathrm{L} \\
\mathrm{M} \\
\mathrm{L} \\
\mathrm{M}\end{array}$ \\
\hline $\begin{array}{l}\text { ST07 - Sodium Technology Knowledge Management } \\
\text { Seismic isolators }\end{array}$ & $\mathrm{H}$ & $\mathrm{X}$ & $\mathrm{X}$ \\
\hline
\end{tabular}

\subsubsection{Regulatory Considerations}

Similar to the previous category, the reduced size of ASM-SFRs has no appreciable impact on the findings of the SNL gap analysis in regard to sodium technology. Instead, the major regulatory issues are associated with tangential topics; the first being the containment design basis. In LWRs, the calculated pressure rise due to a loss-of-coolant accident serves as the design basis for 
containment integrity (GDC-50) [14]. Due to the low operating pressure of the primary sodium in SFRs, the challenge to the reactor containment from a primary pressure boundary breach is minimal. Instead, the major concern would be a temperature increase within the containment from a sodium fire, which could occur during operation or reactor shutdown. This is a fundamental change in the licensing safety case.

The NRC staff recommended a change to a functional containment performance standard in SECY-93-092 [15], which was approved by the commission in the July 30, 1993 SRM to SECY93-092. The staff then recommended the use of functional performance requirements to establish the acceptability of containment in SECY-03-0047 [16], but the commission did not approve due to insufficient information. This issue was revisited in SECY-05-0006 [17], which reviewed concepts from the previous SECYs, but the concepts were not sent to the commission. During recent interactions with NGNP, the NRC staff once again stated a willingness to consider alternative functional containment performance criteria, and deemed the NGNP functional containment performance proposal "reasonable." However, due to the regulatory uncertainty associated with the various proposals for LBE selection, the design basis event for a SFR containment is still unknown. As stated previously, a large sodium fire may be one possibility, as well as an external threat. Similar to the discussion in Section 2.1.2 in regard to LBE selection, what is important for the containment design basis is to ensure that the challenge is due to a mechanistic initiator, and not from a postulated sequence that may not be realizable.

Sodium leaks and fires are not only important because of the potential pressure loading of containment; they can also greatly impact the capacity factor of a plant. Essentially every built and operated SFR has experienced sodium leaks. While the great majority of these events were minor and resulted in little damage, some have proved extremely costly in terms of the ability to restart normal operation of the plant. Perhaps the most well-known example of this followed the sodium leak that occurred at the MONJU facility in Japan. A fire from a sodium leak on the secondary side of the reactor system (non-radioactive sodium) resulted in an almost 15 year shutdown due to regulatory issues. Sodium leaks also greatly impacted the capacity factor during the early years of operation of the Phenix reactor in France. While this issue is unlikely to preclude the successful licensing of an ASM-SFR, there are significant economic repercussions. While it is expected that the NRC will consider any sodium leak or fire at a plant a serious event, the capacity factor of the plant could be severely impacted if the NRC mandates extended downtime following even minor, non-radioactive incidents.

Lastly, there are regulatory questions regarding instrumentation and control and under-sodium maintenance. The SNL gap analysis noted that these topics were not formally covered by the report, but that they do carry licensing implications. For instrumentation, there are questions concerning sensor reliability in a high temperature sodium environment (many of the undersodium sensors at EBR-II failed over the lifetime of the plant). Some additional research and testing will likely be needed for regulatory acceptability. Also, it is expected that ASM-SFR designs will incorporate digital instrumentation and control, and there is uncertainty regarding their regulatory acceptance. As for maintenance, the major question relates to the regulatory need for under-sodium viewing for in-service inspection. This is another fundamental difference from the current, operating LWR fleet, where the primary fluid is transparent, making inspection 
straightforward. It is possible that the NRC may require under-sodium viewing technologies as part of their regulatory oversight of in-service inspection.

Taking the category as a whole, the regulatory issues with the highest priority are likely the selection of the containment design basis, the qualification of equipment and instrumentation, and regulatory issues concerning sodium leaks and fires. Differing SFR designs may propose different containment design bases, and the NRC is unlikely to provide any guidance related to this topic beyond the statements made during past SFR reviews and recent NGNP interactions. As for the qualification of equipment, the NRC already has processes to accomplish this task, but there may be a need for clarification in regards to applying these procedures to SFR technology and the requirements of testing and experimental data. Sodium leaks are unlikely to disrupt the licensing process, but could harm the economic performance of the reactor. Guidance from the NRC regarding a delineation of regulatory responses depending on the significance of leaks and fires could ease investor fears concerning the issue. 


\subsection{Fuels and Materials}

\subsubsection{SNL Safety and Licensing Research Plan Summary}

The fuels and materials gap analysis centered on the licensability of SFR fuels and in-core materials [2] (ex-core material information was derived from a previous report [18]). The ten topical gap areas are shown in Table 2-3. Similar to the accident initiator and sequence gap analysis, the major conclusion of the fuels and material analysis was that the current state of SFR knowledge was sufficient for the design and licensing of an SFR within the envelope of the existing database. The current database would include fuels with $\leq 10 \%$ burnup, oxide or metallic, peak cladding temperature $\leq 600^{\circ} \mathrm{C}$, peak dpa of $\leq 100$, and that have not been reprocessed. A 2007 report on the status of U.S. SFR fuels [19] provides more information on the current state of U.S. SFR fuel knowledge. While Table 2-3 contains many topics that have a low state of knowledge, most of these gaps are related to fuel performance at high $(>10 \%)$ burnup levels, which is considered outside the envelope of the existing database. Several knowledge preservation topics also received a low ranking, since at the time of the report's publication, there were no dedicated efforts for retaining past fuels and materials knowledge.

Table 2-3: Fuels and Materials Gap Topical Areas [2]

\begin{tabular}{|c|c|c|}
\hline Gap Topical Areas & $\begin{array}{c}\text { Importance to } \\
\text { Safety Within } \\
\text { Category } \\
\end{array}$ & $\begin{array}{c}\text { State of } \\
\text { Knowledge }\end{array}$ \\
\hline FM01 - High Burnup Fuel Characterization & $\mathrm{H}$ & \\
\hline Fuel swelling and fuel cladding mechanical interactions (FCMI) above $10 \mathrm{at} \%$ burnup & & M \\
\hline Gas release above 20 at $\%$ burnup & & $\mathrm{L}$ \\
\hline Fuel cladding chemical interactions (FCCI) above $10 \mathrm{at} \%$ burnup & & M \\
\hline FM02 - Fission Product Carryover Fuel Characterization & $\mathrm{H}$ & \\
\hline Fuel swelling and FCMI above 10 at $\%$ burnup & & M \\
\hline Gas release above 20 at $\%$ burnup & & $\mathrm{L}$ \\
\hline FCCI at all burnups & & $\mathrm{L}$ \\
\hline FM03 - Minor Actinide Carryover Fuel Characterization & $\mathrm{H}$ & \\
\hline Fuel swelling and FCMI at all burnups & & $\mathrm{L}$ \\
\hline Gas release above 20 at $\%$ burnup & & $\mathrm{L}$ \\
\hline FCCI at all burnups & & $\mathrm{L}$ \\
\hline FM04 - Advanced Cladding and Duct Fabrication, HT-9, 9Cr-1Mo, ODS & $\mathrm{H}$ & \\
\hline Advanced cladding and duct fabrication, HT-9, 9Cr-1Mo, ODS & & M \\
\hline FM05 - Advanced Cladding and Duct Material Properties & $\mathrm{H}$ & \\
\hline Creep rate at high temperature and dpa levels. & & M \\
\hline FM06 - Duct/Bundle Performance Experience & $\mathrm{H}$ & \\
\hline Potential loss of historical database & & $\mathrm{L}$ \\
\hline Bundle-bundle interactions at all temperatures and dpa levels & & M \\
\hline Bundle-duct interactions at all temperatures and dpa levels & & M \\
\hline FM07 - Structural Materials Issues, Rotating Plug, IHX, EM Pump & M & \\
\hline Rotating plug general knowledge & & $\mathrm{L}$ \\
\hline Intermediate heat exchanger degradation mechanisms & & M \\
\hline Electromagnetic pump fabrication and operational experience for large pumps & & $\mathrm{L}$ \\
\hline FM08 - Brayton $\left(\mathrm{S} / \mathrm{CO}_{2}\right)$ Materials Issues & $\mathrm{H}$ & \\
\hline Brayton $\left(\mathrm{S} / \mathrm{CO}_{2}\right)$ materials issues & & $\mathrm{L}$ \\
\hline FM09 - SFR Fuels and Materials Knowledge Base Preservation & $\mathrm{H}$ & \\
\hline SFR fuels and materials knowledge base preservation & & $\mathrm{L}$ \\
\hline FM10 - Fuel Performance Code Documentation and Training Issues & $\mathrm{H}$ & \\
\hline Fuel performance and code documentation and training issues & & $\mathrm{L}$ \\
\hline
\end{tabular}




\subsubsection{Regulatory Considerations}

While ASM-SFRs do not necessarily introduce new regulatory concerns compared to SFRs in general, there are still several major regulatory questions that need to be resolved. The first issue is whether an ASM-SFR would use a fuel type that falls within the existing fuel database. Some ASM-SFR designs are seeking to achieve extended intervals between refueling or no refueling at all. The high burnup and high minor actinide content of such fuels is likely to push the fuel characterization outside of the envelope of the existing database. Major fuel qualification programs are likely necessary for such designs.

Even if a known fuel design is used in a future SFR project, the large time periods that have elapsed between fuel production runs will likely result in some performance changes. This may be used as justification for requiring a new fuel qualification program. Whether for a new fuel design or one previously studied, fuel qualification may be attempted through a "license by test" approach; however, this method of approval has not been used for any U.S. licensed reactor. Currently, the NGNP project is proposing such a path through the Advanced Gas Reactor fuel development and qualification program. As stated in Section 1.2, the NRC has found this approach reasonable. Another way the NRC could approve the licensing of a plant is through the successful operation of a prototype plant [20]. However, the NRC has not expanded on the specific restrictions that will be placed on the plant, in terms of limits on siting, safety features, or operational conditions, since there is not a current license application pursuing the approach [21].

Next is an issue touched on in the SNL gap analysis report [2], which stated that even if known fuels are used, "existing data must be retrievable and in a form, from a quality assurance standpoint, that is acceptable to the licensing body." It is unclear what information the NRC will require for licensing. For fuel testing data, will the original sources of data be needed (and evaluated), or will summary results be sufficient? The answer to this question will greatly impact the needs of knowledge preservation efforts. Also, much of the testing was conducted under research and development protocol, rather than a regulatory protocol. The exact procedure for assessing these tests for licensing needs further clarification.

The topic of core bowing, which was not directly addressed by the SNL gap report, is an issue that has both material and modeling regulatory implications. Many foreign SFRs do not take advantage of core bowing due to differing design philosophies. Therefore, many foreign regulators simply ignore core bowing during licensing analyses. Core bowing is an important reactivity feedback mechanism in many SFR designs considered in the U.S with a core restraint system based on the limited free-bow concept. Although performance of an SFR design with such a core restraint system was demonstrated with FFTF, it is unclear how the NRC will approach this issue. Without the inclusion of core bowing effects, the safety case during unprotected accidents (i.e., accidents with a failure to SCRAM) for SFRs fundamentally changes. During PRISM interaction with the NRC, it was signaled that the inherent core reactivities would be measured during every startup [22]. It is unclear whether the NRC would currently accept this strategy.

Lastly, there are still open questions regarding regulatory approval of such components as electromagnetic (EM) pumps, sodium-to-water heat exchangers, and fuel handling systems. While there is experience building and operating these components, it has not been without some difficulties, as foreign experience with sodium to water heat exchangers has demonstrated [23]. 
The qualification of these components may seem like small regulatory hurdles, but could cause significant delays in the licensing process and may require expensive testing programs.

In summary, the SNL report stated that almost all of the fuels and materials gaps relate to the fact that there has been little attention given to fuel performance code development in the past two decades [2]. These are not mechanistic codes, but are empirically based and interpolate within the existing database [2]. This results in a great deal of importance being placed on the status of the experimental database. Therefore, uncertainties related to the quality of the database, such as what data are acceptable for licensing, have repercussions in regard to the ability to model fuel and material performance. 


\subsection{Source Term Characterization}

\subsubsection{SNL Safety and Licensing Research Plan Summary}

The SNL source term gap analysis focused on the ability to accurately track radionuclides through the fuel, coolant, primary system, containment, and into the environment [2]. Five topical areas were identified by the gap analysis, seen in Table 2-4, each with at least one component critical to the reliability of the source term calculation. As the table shows, the knowledge state regarding all phenomena was considered at least medium, with higher rankings for the state of knowledge associated with radionuclide release from fuel debris and transport within containment.

Table 2-4: Source Term Characterization Gap Topical Areas [2]

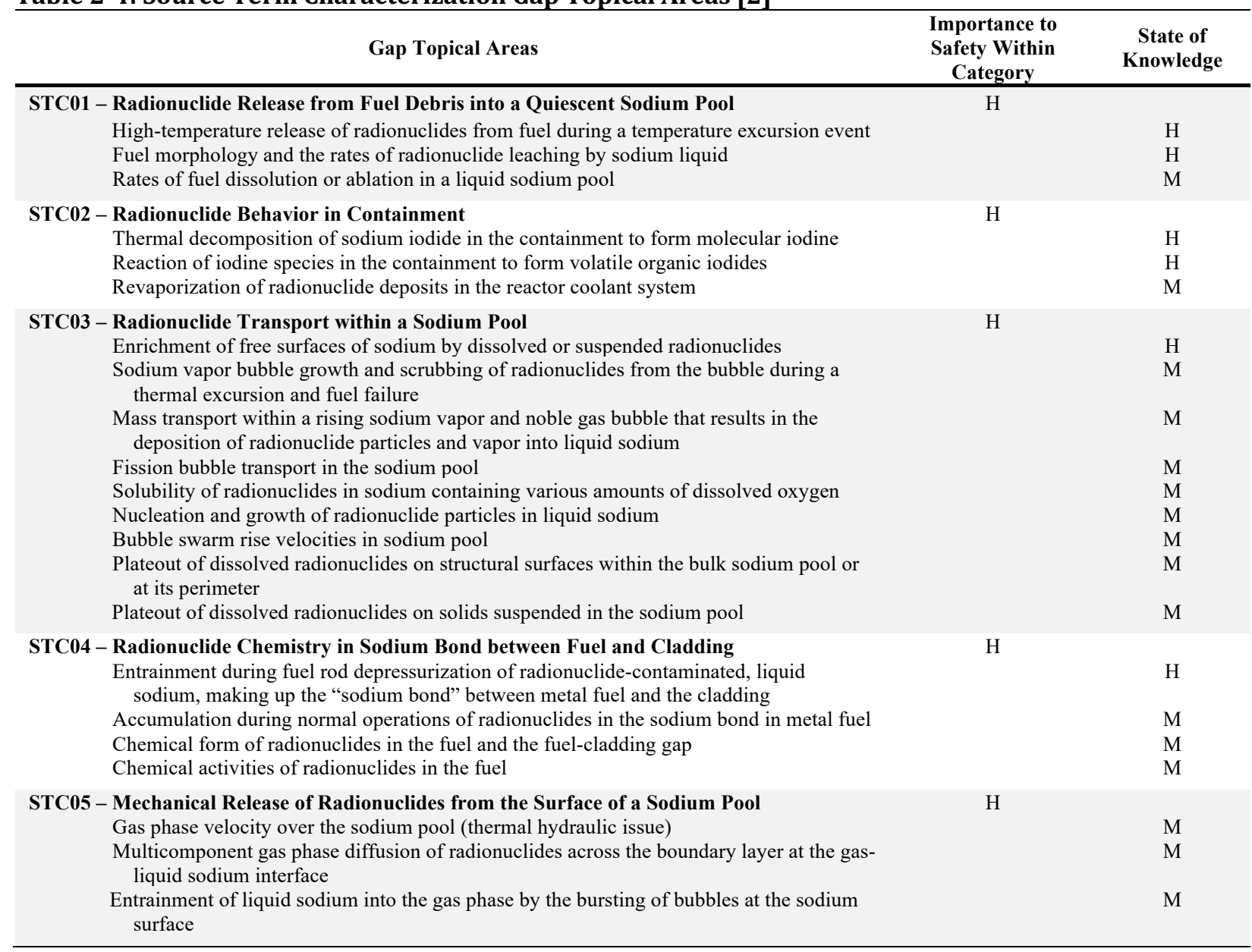

\subsubsection{Regulatory Considerations}

ASM-SFRs face the same difficulties in regard to the source term calculation as other SFR designs; the only difference may be a smaller quantity of radionuclides due to the smaller core size. The NRC has repeatedly suggested the use of a mechanistic source term for advanced reactor designs [15], [16], [24]. However, the NRC requires that sufficient research and testing data should exist to provide "adequate confidence" in the mechanistic approach. Since no reactor design has attempted the U.S. licensing process using a mechanistic source term, it is unclear 
what level of data will be needed to provide adequate confidence. For example, the DOE has conducted many SFR fuel failure tests in the past, but for metal fuel, the tests were limited to transient overpower failures. It is not known whether the relatively limited scope of these fuel tests would be sufficient to satisfy the NRC's requirements regarding licensing with a mechanistic source term.

If the knowledge and tools associated with the mechanistic source term calculation are not considered "adequate" by the NRC, a conservative, postulated source term may be required. Previous, non-mechanistic attempts to characterize SFR source terms have been presented to the NRC in the PSID of both SAFR [25] and PRISM [26]. However, the NRC found significant deficiencies in these source term calculations, as both designs attempted to use scaled oxide fuel radionuclide data to represent metal fuel. In NUREG-1368 [22], the preliminary safety evaluation report (PSER) for PRISM, the NRC identified a "lack of data and analyses to support the assumptions used to estimate the source term," as one of the major sources of uncertainty within the PRA.

The question of mechanistic source term approval is one that has far-reaching implications for all advanced reactor types. Since no past reactor analysis has attempted to characterize a mechanistic source term for licensing, the first design to do so could set a powerful precedent for all subsequent applicants. If an unsatisfactory effort at mechanistic source term modeling is presented to the NRC, a postulated source term could be suggested in its place. This could lead to a source term that would be difficult to bound since it may not be derived from a mechanistic initiator or calculation. Alternative approaches could be presented for ASM-SFRs in place of a potentially more complicated "true" mechanistic source term. Since core inventories are smaller for ASM-SFRs, it might be possible to meet regulatory requirements even with releases above those indicated by mechanistic modeling. However, this potential regulatory path also carries the possible danger of beginning a cycle of unrealistic initiators and releases.

While the SNL report focused on the ability to mechanistically model the source term, the needs of such a simulation will depend on the regulatory requirements. As of now, these requirements, along with those defining the threshold of "adequate confidence," are unclear. Any information that could clarify the regulatory expectations of a mechanistic source term may help prioritize the research and development needs associated with source term creation. 


\subsection{Codes and Models}

\subsubsection{SNL Safety and Licensing Research Plan Summary}

The SNL codes and models gap analysis centered on the state of SFR computer analysis tools and their readiness to support a licensing application [2]. Ten gap topical areas were identified, seen in Table 2-5. In general, the analysis found that while current U.S. codes are primarily legacy tools, they should be sufficient for licensing as long as fuels within the envelope of the existing database are used (as described in Section 2.3.1) and safety margins are significant. If margins are small, then the current suite of SFR safety analysis codes is likely inadequate, even for known fuel types. As mentioned in other gap analysis panels, the state of knowledge regarding the source term release from fuel and seismic data was considered low. This deficiency impacts the ability to model scenarios where significant geometric changes to the core may be encountered. However, since the safety case for SFRs with metallic fuel has historically been based on prevention of core damage, and significant geometric changes are likely to only be encountered during BDBA or lower frequency events, the deficiencies in severe accident modeling were not necessarily seen as an impediment to licensing. Lastly, it should be noted that the SNL gap analysis report only reviewed U.S. codes and models, and at the time of publication, support for U.S. codes such as SAS4A/SASSYS-1 [27] was seen as weak.

Table 2-5: Codes and Models Gap Topical Areas [2]

\begin{tabular}{|c|c|c|}
\hline Gap Topical Areas & $\begin{array}{c}\text { Importance to } \\
\text { Safety Within } \\
\text { Category } \\
\end{array}$ & $\begin{array}{l}\text { State of } \\
\text { Knowledge }\end{array}$ \\
\hline CM01 - Modeling of Seismic Events & $\mathrm{H}$ & \\
\hline Experimental SFR seismic data & & $\mathrm{L}$ \\
\hline Common cause effects of a seismic event on the reactor system & & M \\
\hline $\begin{array}{l}\text { CM02 - Models for Transient Natural Convection Processes in the Reactor System } \\
\text { Modeling of transient natural convection }\end{array}$ & M & M \\
\hline $\begin{array}{l}\text { CM03 - LIFE-Metal/Life } 4 \text { Update } \\
\text { Re-calibration and validation of LIFE-METAL }\end{array}$ & $\mathrm{H}$ & $\mathrm{L}$ \\
\hline $\begin{array}{l}\text { CM04 - Sub-channel and Multi-pin Analysis Capabilities } \\
\text { Sub-channel and multi-pin analysis capability }\end{array}$ & M & $\mathrm{L}$ \\
\hline $\begin{array}{l}\text { CM05 - Modeling of Gas Bubble Entrainment and the Effects of Sodium-Water Interaction } \\
\text { Modeling of Gas Bubble entrainment and the effects of sodium-water interaction }\end{array}$ & M & $\mathrm{L}$ \\
\hline $\begin{array}{l}\text { CM06 - Advanced Fuel Behavior Models to Predict the Margin to Pin Failure for Fuels with } \\
\text { High Actinide Content } \\
\text { High-actinide fuel performance models }\end{array}$ & $\mathrm{H}$ & $\mathrm{L}$ \\
\hline $\begin{array}{l}\text { CM07 - Models to Predict Source Term Releases from Fuel in LMR Accidents } \\
\text { Predict source term releases from fuel in LMR accidents }\end{array}$ & $\mathrm{H}$ & $\mathrm{L}$ \\
\hline $\begin{array}{l}\text { CM08 - SAS4A Code Modernization, Support, and Knowledgeable User Base } \\
\text { Support updating the memory management scheme to remove various nodalization limits } \\
\text { Support parallel applications } \\
\text { Create an input processor and user interface to improve use friendliness and reduce } \\
\text { potential input errors }\end{array}$ & $\mathrm{H}$ & $\begin{array}{l}\mathrm{L} \\
\mathrm{L} \\
\mathrm{L}\end{array}$ \\
\hline $\begin{array}{l}\text { CM09 - MELCOR/CONTAIN-LMR Update } \\
\text { MELCOR/CONTAIN-LMR update }\end{array}$ & $\mathrm{H}$ & $\mathrm{L}$ \\
\hline $\begin{array}{l}\text { CM10 - Fuel Performance Code Documentation and Training Issues } \\
\text { Documentation of LIFE-METAL }\end{array}$ & $\mathrm{H}$ & $\mathrm{L}$ \\
\hline
\end{tabular}

\subsubsection{Regulatory Considerations}

The characteristics of ASM-SFRs should not affect the conclusions of the SNL Safety and Licensing Research Plan in regards to codes and models. However, the more general issues 
identified by the report remain, including the qualification of research and development computer codes for regulatory analysis and the potentially insufficient ability to properly model benign termination of severe accidents and seismic events. The first issue pertains to establishing NQA-1 [12] compliance for computer codes that were developed for DOE reactor research, which includes codes like SAS4A/SASSYS-1 [27]. While it may take a great deal of effort to achieve NQA-1 compliance, it should not take considerable regulatory interaction in order to clarify the path forward. Part of these interactions may involve reviewing the applicability of past guidance documents, such as RG 1.203 [28], for advanced reactors. The second issue related to code capability might be the harder issue to address. As discussed in Section 2.3 and 2.4, there are gaps related to the fuel characterization and performance knowledge database. Without clear requirements related to fuel performance and assessing the mechanistic source term, it is difficult to set the needs of the severe accident codes and models. This is true whether qualifying an existing code, or creating a new code, if the ASM-SFR vendor chose to do so.

There is also an open regulatory question related to the mechanistic modeling of accident scenarios in general, including the performance of passive systems. Most ASM-SFR designs rely on natural circulation both in the primary system and in decay heat removal systems during accidents. Properly characterizing flow paths and possible changes to boundary conditions that could disrupt system performance may require high-fidelity computational fluid dynamic (CFD) tools. However, there are regulatory hurdles regarding the acceptability of CFD analyses for licensing, especially when analyzing fluids other than water. This introduces the odd scenario where systems-analysis codes tools may be required for thermohydraulic analyses even though higher-fidelity tools exist (although they may have limited validation). In past SFR analyses, the NRC was quick to point out a lack of mechanistic modeling within the PRA as a major deficiency. In the review of the SAFR PRA [29], the NRC stated that during fuel damage "mechanistic analyses have not been performed that could otherwise support the generic sequences in this portion of the PRA." The NRC had similar criticisms for the PRISM PRA.

As mentioned in Section 2.1.2, the requirements related to seismic analysis are likely to change as post-Fukushima recommendations are instituted. It is still unknown what the final regulatory requirements will look like, but new seismic analysis methods may be needed, such as an integrated seismic, structural, and systems-analysis approach. As stated in the previous section, simulating the plant response to seismic events was seen as one the weakest areas of SFR modeling currently, since there are few data on the movement of coolant during seismic sequences or the distortion of the core and associated structures. This issue intersects with the qualification of seismic isolators and the necessary testing and modeling for regulatory approval.

In summary, the most pressing gaps related to codes and models are the need for clarification regarding the process for regulatory acceptance of DOE reactor research codes, such as SAS4A/SASSYS-1, and regulatory requirements for fuel characterization and mechanistic source term analyses. The first issue should need less NRC input to address, since the NRC already has code qualification procedures in place for LWR codes and models. The only question is whether any changes would need to be made to existing qualification procedures for them to be applicable to SFR codes and models. 


\section{Possible Pathways Forward}

This section outlines several gap topical areas that could possibly be addressed during initial RTDP interactions with the NRC. Each subsection reviews the regulatory importance of the topic, the current state of knowledge, along with any ongoing research and development before rating the suitability of the topic for NRC interaction.

\subsection{Codes and Models}

The codes and models topic relates to the regulatory approval of SFR design and safety analysis tools, including the possible conversion of former R\&D codes.

\section{Regulatory Importance}

The qualification of SFR design and safety analysis tools is essential to completing a licensing safety analysis.

\section{Current Knowledge State}

As discussed in Section 2.5, while most U.S. SFR analysis tools are primarily legacy codes, there have been past validation efforts and an extensive user history. The important question centers on the state of acceptability of such codes for licensing. While the sodium-fire and sodium-concrete interaction analysis capabilities of CONTAIN-LMR are currently being integrated into MELCOR (an NRC approved code for LWR applicants), SAS4A/SASSYS-1 remains as an R\&D tool that will need additional approval for regulatory analysis. There is uncertainty associated with the requirements to achieve its regulatory acceptance.

\section{Current Research and Development}

There are currently several projects to support continued development and validation of SFR design and safety analysis codes and methods:

1) SAS4A/SASSYS-1 Modernization and Maintenance (T. Fanning, ANL) - Includes efforts to remove applied technology designation, add new models for subchannel analysis, actinide bearing fuels, interface for CFD tools, and the improvement of code structure and documentation.

2) MELCOR CONTAIN-LMR Integration (M. R. Denman, SNL) - Provide CONTAINLMR sodium accident analysis capability within MELCOR structure, including models for sodium pool and spray fires, and sodium-concrete interactions.

3) International Passive Safety Benchmarking (L. L. Briggs, ANL) - International benchmarking project based on EBR-II inherent safety demonstration tests (SHRT-17 and 45R). Includes 20 organizations from 11 countries.

4) Benchmark Analysis of FFTF Passive Safety Demonstration Test (D. Wootan, PNNL) Prepare benchmark specifications for the key FFTF passive safety demonstration test (unprotected loss of flow test from reduced power) to support validation of systems design and safety analysis codes under bilateral collaborations. 
5) Metal Fuel Failure Analysis (A. M. Tentner, ANL) - Development of metal-alloy fuel pin failure analysis capabilities of the SAS4A code in response to severe accident initiators (margin-to-failure assessments, transient FCMI and FCCI analyses, reactivity effects of in- and ex-pin molten fuel motion, fuel-coolant interactions, coolant channel blockages, etc.).

\section{NRC Priority}

The codes and models issue may be a good initial topic for discussion with the NRC. There is a reasonable amount of current work taking place regarding this subject, and a qualification plan could be developed concerning specific codes and models. This plan could be established through industry and national laboratory collaboration, in order to formulate and prioritize the requirements for codes developed by the national laboratories. Discussion with the NRC would then center on this proposed approach and the NRC could provide insight into possible modifications in order to meet regulatory requirements. The ability to reference specific codes may increase the likelihood of receiving constructive feedback from the NRC, rather than general comments or the deferment of judgment until specific details are clarified. The results of the interaction may also benefit other reactor types, where research codes need to be adapted for licensing. Lastly, this discussion could also bear fruit in regards to the regulatory acceptability of CFD and other advanced modeling techniques. 


\subsection{Database Quality}

Database quality refers to the level of detail included in the fuel qualification and component reliability databases, which will be subject to regulatory review. In particular, there is uncertainty related to whether the NRC will require primary documents from past testing programs, or summary data.

\section{Regulatory Importance}

Fuel testing data will be necessary for reactor licensing. An ample reliability database will be helpful for the creation of a PRA that can be used not only as part of the licensing safety case, but for the selection of LBEs as well.

\section{Current Knowledge State}

It is currently unclear what data the NRC will require for the licensing of a SFR. In particular, it is not known whether the NRC will require data from original tests and equipment failures, or whether summarized data will be adequate for fuel/component qualification and to quantify the PRA.

\section{Current Research and Development}

There are several knowledge preservation efforts currently underway:

1) EBR-II Shutdown Heat Removal Test (SHRT) Database (T. Sofu, ANL)

2) TREAT Test Database (A. E. Wright, ANL)

3) FFTF Passive Safety Testing Database (D. Wootan, PNNL)

4) EBR-II Metal Fuel Irradiation Test Database (A. Yacout, ANL)

5) EBR-II Physics Analysis Database (T. K. Kim, ANL)

6) Fast Reactor Reliability Database (M. R. Denman, SNL and D. Grabaskas, ANL)

\section{NRC Priority}

The database quality topic may be a good first choice for NRC interaction, although there is a danger that the NRC will not clarify what data are necessary for licensing without a detailed design. However, any additional guidance provided by the NRC could be beneficial for the many ongoing knowledge preservations efforts. So although the NRC may fall back on general policy statements if clear and precise questions are not posed, overall, the importance of the topic for fuel characterization and PRA development, along with the benefit to current preservation efforts, makes the database quality an acceptable topic for initial NRC interactions. 


\subsection{Sodium Leaks/Fires}

Sodium leaks/fires refers to the regulatory response to the events in terms of impact on the capacity factor of the plant. This also includes non-radioactive sodium leaks from the secondary system and sodium-water interactions from steam generator leaks.

\section{Regulatory Importance}

This issue is unlikely to impede plant licensing, but the economic repercussions of the issue could affect project investment.

\section{Current Knowledge State}

There have been many sodium leaks at SFRs globally, with the majority being minor events. In the U.S., EBR-II experienced approximately 30 small leaks and one significant leak during its 30 years of operation. While the issue of sodium leaks/fires was discussed during the PRISM and SAFR licensing efforts, the NRC interactions centered on the prevention and safety consequences of the accidents, such as containment pressure loading, not the regulatory response.

\section{Current Research and Development}

There are no current DOE projects related to sodium leaks/fires.

\section{NRC Priority}

The issue of sodium leaks/fires is a relatively good topic for initial NRC interactions. The goal of the discussion would be to obtain information regarding how the $\mathrm{NRC}$ would differentiate their response to different categories of sodium leaks and fires. For example, "would small leaks that resulted only in insulation smoldering be treated the same as larger fires", or "would there be reduced regulatory response if the room in which the leak occurred is designed to accommodate sodium spills and fires (e.g., metal liners)?" Since the U.S. has a long history of sodium reactor development, past leaks and fires could be examined to identify the types of issues a future plant could expect to encounter. Even if the NRC does not offer clear guidance regarding their response to an incident, establishing the topic with the NRC and highlighting the need for resolution could help investor prospects. 


\subsection{Seismic Isolators}

The topic of seismic isolators refers to the regulatory qualification and approval of seismic isolators for the reactor building.

\section{Regulatory Importance}

Seismic isolator qualification will be necessary for the licensing safety analysis of current SFR designs. If credit cannot be taken for seismic isolation, it will fundamentally change the seismic event analysis for SFRs.

\section{Current Knowledge State}

No licensed U.S. reactor has used seismic isolators. Two previous SFR designs that included seismic isolators, PRISM and SAFR, did have interactions with the NRC concerning this topic through their PSIDs. In the PSER for the PRISM design, the NRC required that the results of the seismic isolator qualification program (that was to take place at ANL) were to be reported to the NRC for regulatory review [22]. However, these programs were terminated before the qualification program could be completed.

\section{Current Research and Development}

There are no current DOE projects related to seismic isolators.

\section{NRC Priority}

The establishment of seismic isolator qualification requirements may be an acceptable topic for initial NRC interactions. However, there is the possibility that the NRC will defer any substantive statements until after the completion of a seismic testing program (similar to the statements made for PRISM). On the positive side, interactions with the NRC could also provide insight into qualification programs for other components, such as EM pumps, sodium-to-water steam generators, and fuel-handling mechanisms. 


\subsection{Accident Initiators}

Accident initiators refer to the identification of initiating events to be included as part of the LBEs.

\section{Regulatory Importance}

The identification and classification of LBEs is a necessary step of the licensing process, and serves as the basis for determining the necessary regulatory criteria for specific incidents.

\section{Current Knowledge State}

For this topic, the knowledge state can be split into two categories:

1) Knowledge state regarding ASM-SFR accident initiators: The current knowledge state is dependent on the historic experience with a specific SFR design. For known ASM-SFR designs, as defined in Section 2.1.1, the knowledge state is likely adequate for licensing.

2) Knowledge state regarding ASM-SFR LBE selection: While some regulatory interaction occurred during the design process of CRBR, PRISM, and SAFR, the cancellation of these projects before final licensing approval resulted in the lack of definitive rulings by the NRC on some topics. LBE selection processes were proposed by the NRC during PRISM and SAFR interactions, but they were deterministic selection methods, only supplemented with PRA insights. Recent NGNP/NRC interactions have included discussions of a new, frequency-based LBE selection structure using results from the PRA.

\section{Current Research and Development}

While there are no current DOE projects directly related to SFR accident initiators, there are several tangential projects, like the Brayton cycle development work taking place at SNL, and the natural circulation decay heat removal experiments at ANL. There is also an ongoing effort, described in Section 3.2, to collect reliability data to quantify the frequency of accident initiators and sequences within the PRA. On the regulatory front, NGNP interactions have laid the groundwork for alternative LBE selection processes.

\section{NRC Priority}

The identification of accident initiators is likely a poor choice for initial NRC interaction. Without design specifics, it is probable that the NRC will defer any final decisions until more detail is available. If the goal is to establish more general LBE criteria that any advanced reactor type can follow, the NGNP interactions have already pursued this path, and have essentially reached the end of NRC feedback without specific design considerations. 


\subsection{Mechanistic Source Term}

The mechanistic source term topic refers to the ability to accurately track radionuclides through the fuel, coolant, primary system, containment, and into the environment and the regulatory definition of sufficient data and knowledge regarding the criteria for adequate confidence in the mechanistic approach.

\section{Regulatory Importance}

The mechanistic source term analysis will be a vital part of the licensing safety case for any future SFR design and signifies a substantial deviation from the current licensing approach of the operating LWR fleet.

\section{Current Knowledge State}

As with previous topics, the knowledge base can be split into two separate topics:

1) Knowledge of SFR fuel behavior during accidents that lead to core damage: Current state of SFR fuel knowledge is a function of the type of fuel chosen, and the data requirements of the regulatory body. However, in general the knowledge of fuel movement and transport during severe accidents is considered low.

2) Knowledge of mechanistic source term use during licensing: No U.S. reactor has completed the licensing process using a mechanistic source term, and only preliminary discussions have taken place with the NRC regarding how the process would be conducted.

\section{Current Research and Development}

There are no current projects related to the characterization of fuel during severe accidents. However, there are efforts currently taking place to preserve past SFR fuel knowledge, as described in Section 3.2. There is also an effort to integrate CONTAIN-LMR into MELCOR, as discussed in Section 3.1, but this project centers on the transfer of sodium fire models as the original CONTAIN-LMR models were developed for oxide fuel only.

\section{NRC Priority}

Overall, the topic of the mechanistic source term characterization is a poor choice for initial regulatory interaction. The topic is incredibly important to the licensing of all future advanced reactor designs. Any precedent set during NRC discussions could have long-lasting effects on the advanced reactor industry. While this illustrates why this topic needs additional regulatory clarification, it also demonstrates why this issue must be approached in a well-thought-out and comprehensive manner. Also, the NRC is unlikely to provide tangible guidance without the application of a specific reactor design. Because of this, the topic of a mechanistic source term should not be chosen as the trial topic to begin NRC interactions within the RTDP. 


\subsection{Summary}

Table 3-1 presents an overview of the regulatory importance and estimated lead time for the topics reviewed in the previous sections. Codes and models are essential for licensing and have a medium lead time, since improvements and modifications might be needed before beginning the qualification process. Along the same lines, the database quality has a high importance for licensing, but also may need extended time for qualifying data (or possibly a long lead time to obtain new data to fill deficiencies). Sodium leaks/fires have a low regulatory importance (in the context discussed here), but also a short lead time, since only discussions with the NRC are likely to be needed. Seismic isolators are very important to current SFR designs, but not mandatory for licensing. However, if seismic isolators are incorporated into specific SFR designs presented to the NRC, there is likely to be a long lead time for development of a qualification program. Accident initiators are fairly well known based on previous SFR licensing efforts and are unlikely to derail licensing. Since the accident initiator topic will be based mostly on NRC discussions, the lead time is considered low. Finally, the mechanistic source term is essential for licensing, and is likely to have a long lead time since new data might be necessary and tool development may take prolonged effort.

\begin{tabular}{ccc} 
Table 3-1: Summary of Topic Importance and Lead Time \\
\hline Topic & $\begin{array}{c}\text { Importance } \\
\text { to Licensing }\end{array}$ & Lead Time \\
\hline Codes and Models & High & Medium \\
Database Quality & High & Medium \\
Sodium Leaks/Fires & Low & Short \\
Seismic Isolators & Medium & Long \\
Accident Initiators & Medium & Short \\
Mechanistic Source Term & High & Long \\
\hline
\end{tabular}

Table 3-2 summarizes the ranking of topics for initial NRC RTDP interactions, based on DOE expert opinion. Codes and models and database quality both rank high since detailed questions can be posed to the NRC regarding specific issues, without the need for a specific SFR design. Sodium leaks/fires is also considered high since simply establishing a dialogue with the NRC could produce benefits, and design specifics are probably not needed. Seismic isolation is next, since there has already been previous interaction with the NRC, and the NRC may be willing to address the issue separately from specific SFR designs. Lastly, both accident initiators and mechanistic source term development are ranked low since the NRC may be unwilling to provide definitive guidance without detailed designs, and there are large implications for all future advanced reactor licensing efforts. 
Table 3-2: Possible Path Forward Overview

\begin{tabular}{|c|c|c|}
\hline Topic & $\begin{array}{l}\text { Initial NRC } \\
\text { Interaction } \\
\text { Ranking } \\
\end{array}$ & Explanation \\
\hline Codes and Models & High & $\begin{array}{l}\text { Detailed questions regarding specific codes and models increase the } \\
\text { likelihood of constructive feedback. Guidance for LWR codes is already } \\
\text { in place. Minimal NRC input should be needed for substantial gain. }\end{array}$ \\
\hline Database Quality & High & $\begin{array}{l}\text { Detailed questions regarding specific data issues increase the likelihood } \\
\text { of constructive feedback. Many ongoing efforts involving knowledge } \\
\text { preservation. Important for fuel qualification, codes/methods validation, } \\
\text { and PRA quantification. }\end{array}$ \\
\hline Sodium Leaks/Fires & High & $\begin{array}{l}\text { Detailed questions could be presented regarding the NRC's regulatory } \\
\text { response to sodium leak/fire events. Simply establishing a dialogue with } \\
\text { the NRC concerning the topic could increase investor confidence and } \\
\text { NRC's familiarity with sodium technology. }\end{array}$ \\
\hline Seismic Isolators & Medium & $\begin{array}{l}\text { Could build on previous SAFR and PRISM discussions. Relatively well } \\
\text { known design. May be able to provide qualification requirements } \\
\text { without a detailed small SFR design. }\end{array}$ \\
\hline Accident Initiators & Low & $\begin{array}{l}\text { Can be very design dependent, reducing the likelihood of constructive } \\
\text { feedback. Substantial NRC feedback exists regarding past U.S. designs. } \\
\text { Preferred direction for LBE selection process still uncertain. }\end{array}$ \\
\hline $\begin{array}{c}\text { Mechanistic Source } \\
\text { Term }\end{array}$ & Low & $\begin{array}{l}\text { Can be very design dependent, reducing the likelihood of constructive } \\
\text { feedback. Substantial impact on all future advanced reactor designs. } \\
\text { Long lead time. Could result in postulated requirements. }\end{array}$ \\
\hline
\end{tabular}




\section{References}

[1] U.S. Department of Energy, "Regulatory Technology Development Plan for the Standard Modular High-Temperature Gas-Cooled Reactor," DOE-HTGR-86-064, 1987.

[2] Denman, M. et al., "Sodium Fast Reactor Safety and Licensing Research Plan - Volume 1," Sandia National Laboratories, SAND2012-4260, 2012.

[3] "Energy Policy Act," Public Law 109-58, 119 Stat. 594, 2005.

[4] U.S. Nuclear Regulatory Commission and Department of Energy, "Next Generation Nuclear Plant Licensing Strategy, A Report to Congress," 2008.

[5] Gibbs, G.A., Idaho National Laboratory letter to U.S. Nuclear Regulatory Commission, "Contract No. DE-AC07-05ID14517 - Next Generation Nuclear Plant Licensing White Paper Submittal - Next Generation Nuclear Plant Licensing Basis Event Selection - NRC Project \# 0748," INL/EXT-10-19521, 2010.

[6] Gibbs, G. A., Idaho National Laboratory letter to U.S. Nuclear Regulatory Commission, "Contract No. DE-AC07-05ID14517 - Next Generation Nuclear Plant Licensing White Paper Submittal - Next Generation Nuclear Plant Defense-in-Depth Approach - NRC Project \# 0748," INL/EXT-09-17139, 2009.

[7] Gibbs, G. A., Idaho National Laboratory letter to U.S. Nuclear Regulatory Comission, "Contract No. DE-AC07-05ID14517 - Next Generation Nuclear Plant Licensing White Paper Submittal - Mechanistic Source Terms - NRC Project \# 0748," INL/EXT-10-17997, 2010.

[8] U.S. Nuclear Regulatory Commission, Office of New Reactors, "Summary Feedback on Four Key Licensing Issues - Next Generation Nuclear Plant," DRAFT, 2013.

[9] U.S. Nuclear Regulatory Commission, "Staff Review of Generation IV International Forum report, 'Safety Design Criteria for Generation IV Sodium-Cooled Fast Reactor System'," 2013.

[10] U.S. Nuclear Regulatory Commission, "Near-term Report and Recommendations for Agency Actions following the Events in Japan," SECY-11-0093, 2011.

[11] Grabaskas, D. and Sofu, T., "Review of Passive System Reliability Modeling Approaches for Advanced Small Modular Reactors," Proceedings of the International Topical Meeting o Probabilistic Safety Assessment and Analysis (PSA 2013), 2013.

[12] American Society of Mechanical Engineers, "NQA-1 Quality Assurance Requirements for Nuclear Facility Applications," NQA-1a-2009, 2009.

[13] U.S. Code of Federal Regulations, "Quality Assurance Criteria for Nuclear Power Plants and Fuel Reprocessing Plants," 10 CFR 50 Appendix B, 2007.

[14] "General Design Criteria for Nuclear Power Plants," 10 CFR 50 Appendix A, 2007.

[15] U.S. Nuclear Regulatory Commission, "Issues Pertaining to the Advanced Reactor (PRISM, MHTGR, and PIUS) and CANDU 3 Designs and Their Relationship to Current Regulatory Requirements," SECY-93-092, 1993.

[16] U.S. Nuclear Regulatory Commission, "Policy Issues Related to Licensing Non-Light-Water Reactor Designs," SECY-03-0047, 2003.

[17] U.S. Nuclear Regulatory Commission, "Second Status Paper on the Staff's Proposed Regulatory Structure for New Plant Licensing and Update on Policy Issues Related to New 
Plant Licensing," SECY-05-0006, 2005.

[18] Chopra, O.K. and Natesan, K., "Structural Materials for Advanced Burner Reactors," Unpublished Report, 2007.

[19] Crawford, D., Porter, D., and Hayes, S., "Fuels for Sodium-cooled Fast Reactors: US Perspective," Journal of Nuclear Materials, vol. 371, pp. 202-231, 2007.

[20] U.S. Code of Federal Regulations, "Addtional Standards and Provisions affecting Class 103 Licenses and Certification for Commercial Power," 10 CFR 50.43(e)(2), 2007.

[21] U.S. Nuclear Regulatory Commission, "Staff Assessment of Selected Small Modular Reactor Issues Identified in SECY-10-0034," SECY-11-0112, 2011.

[22] U.S. Nuclear Regulatory Commission, "Preapplication Safety Evaluation Report for the Power Reactor Innovative Small Module (PRISM) Liquid-Metal Reactor," NUREG-1368, 1989-1994.

[23] International Atomic Energy Agency, "Liquid Metal Cooled Reactors: Experience in Design and Operation," IAEA-TECDOC-1569, 2007.

[24] U.S. Nuclear Regulatory Commission, Office of New Reactors, "Assessment of White Paper Submittals on Fuel Qualification and Mechanistic Source Terms - Next Generation Nuclear Plant - Project 0748," ML120240669, 2013.

[25] U.S. Department of Energy, "SAFR - Sodium Advanced Fast Reactor, Preliminary Safety Information Document," AI-DOE-13527, 1985.

[26] General Electric, "Power Reactor Innovative Small Module (PRISM), Preliminary Safety Information Document," GEFR-00793, 1987.

[27] Editor: T. H. Fanning, "The SAS4A/SASSYS-1 Safety Analysis Code System: User's Guide," Nuclear Engineering Division, Argonne National Laboratory, ANL/NE-12/4, 2012.

[28] U.S. Nuclear Regulatory Commission, "Transient and Accident Analysis Methods," RG $1.203,2005$.

[29] U.S. Nuclear Regulatory Commission, "Preapplication Safety Evaluation Report for the Sodium Advanced Fast Reactor (SAFR)," NUREG-1369, 1991. 


\section{Argonne}

Nuclear Engineering Division

Argonne National Laboratory

9700 South Cass Avenue, Bldg. 208

Argonne, IL 60439-4842

www.anl.gov 